Maria Miranda ORCID iD: 0000-0003-0862-2122

\title{
RAPID AND COST-EFFECTIVE PROCESS BASED ON INSECT LARVAE FOR SCALE-UP PRODUCTION OF SARS-COV-2 SPIKE PROTEIN FOR SEROLOGICAL COVID-19 TESTING
}

Smith, Ignacio ${ }^{1,2}$, Mc Callum Gregorio Juan ${ }^{1,2}$, Sabljic, Adriana Victoria ${ }^{3,4}$, Marfia, Juan Ignacio $^{3,4}$ Bombicino, Silvina Sonia ${ }^{3,4}$, Trabucchi, Aldana, $a^{3,4}$ Iacono, Ruben Francisco ${ }^{3,4}$, Birenbaum, Joaquín Manuel $^{1,2}$, Vazquez, Susana Claudia ${ }^{1,2}$, Minoia, Juan Mauricio ${ }^{1,2}$, Cascone, Osvaldo $^{2,7}$, López, María Gabriela, ${ }^{5,6}$, Taboga, Oscar ${ }^{5,6}$, Targovnik, Alexandra Marisa ${ }^{1,2}$, Wolman, Federico Javier ${ }^{1,2}$, Fingermann, Matías ${ }^{6,7}$, Alonso, Leonardo Gabriel ${ }^{1,2}$, Valdez Silvina Noemí ${ }^{3,4}$ and Miranda, María Victoria ${ }^{1,2}$.

${ }^{1}$ Universidad de Buenos Aires (UBA), Facultad de Farmacia y Bioquímica, Departamento de Microbiología, Inmunología, Biotecnología y Genética, Cátedra de Biotecnologia, Buenos Aires, Argentina

${ }^{2}$ Consejo Nacional de Investigaciones Científicas y Técnicas (CONICET) Universidad de Buenos Aires, Instituto de Nanobiotecnología (NANOBIOTEC) Buenos Aires, Argentina

${ }^{3}$ Universidad de Buenos Aires (UBA), Facultad de Farmacia y Bioquímica, Departamento de Microbiología, Inmunología, Biotecnología y Genética, Cátedra de Inmunología, Buenos Aires, Argentina

${ }^{4}$ Consejo Nacional de Investigaciones Científicas y Técnicas (CONICET) Universidad de Buenos Aires, Instituto de Estudios de la Inmunidad Humoral "Prof. Ricardo A. Margni” (IDEHU), Buenos Aires, Argentina

This article has been accepted for publication and undergone full peer review but has not been through the copyediting, typesetting, pagination and proofreading process, which may lead to differences between this version and the Version of Record. Please cite this article as doi: 10.1002/bit.27889.

This article is protected by copyright. All rights reserved. 
${ }^{5}$ Instituto de Biotecnología, Instituto Nacional de Tecnología Agropecuaria (INTA), Buenos Aires, Argentina

${ }^{6}$ Consejo Nacional de Investigaciones Científicas y Técnicas (CONICET), Buenos Aires, Argentina

${ }^{7}$ Instituto Nacional de Producción de Biológicos (INPB), ANLIS “Dr. Carlos G. Malbrán”, Vélez Sarsfield 563, (1282) Buenos Aires, Argentina

This work was supported by the Agencia Nacional de Promoción de la Investigación, el Desarrollo Tecnológico y la Innovación (ANPCyT) (IP-COVID-19-209).

Abbreviations: SARS-CoV: human severe acute respiratory syndrome coronavirus; S: Spike; ELISA: Enzyme-Linked Immunosorbent Assay

\begin{abstract}
Serology testing for COVID-19 is important in evaluating active immune response against SARSCoV-2, studying the antibody kinetics, and monitoring reinfections with genetic variants and new virus strains, in particular, the duration of antibodies in virus-exposed individuals and vaccinemediated immunity. In this work, recombinant S protein of SARS-CoV-2 was expressed in Rachiplusia nu, an important agronomic plague. One gram of insect larvae produces an amount of S protein sufficient for 150 determinations in the ELISA method herein developed. We established a rapid production process for SARS-CoV-2 S protein that showed immunoreactivity for anti-SARS-CoV-2 antibodies and was used as a single antigen for developing the ELISA method with high sensitivity (96.2\%) and specificity (98.8\%). Our findings provide an efficient and cost-effective platform for large-scale S protein production, and the scale-up is linear, thus avoiding the use of complex equipment like bioreactors.

Graphical Abstract
\end{abstract}

This article is protected by copyright. All rights reserved. 

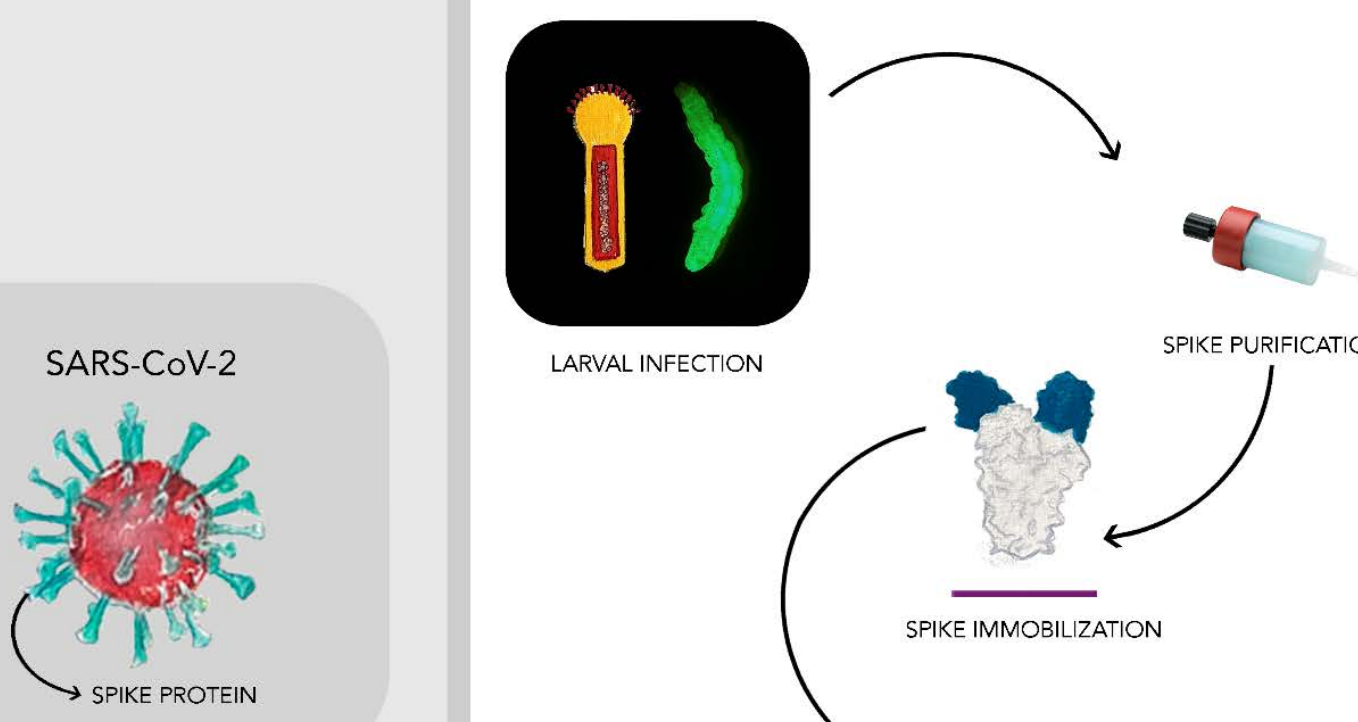

LARVAL INFECTION

SPIKE PURIFICATION

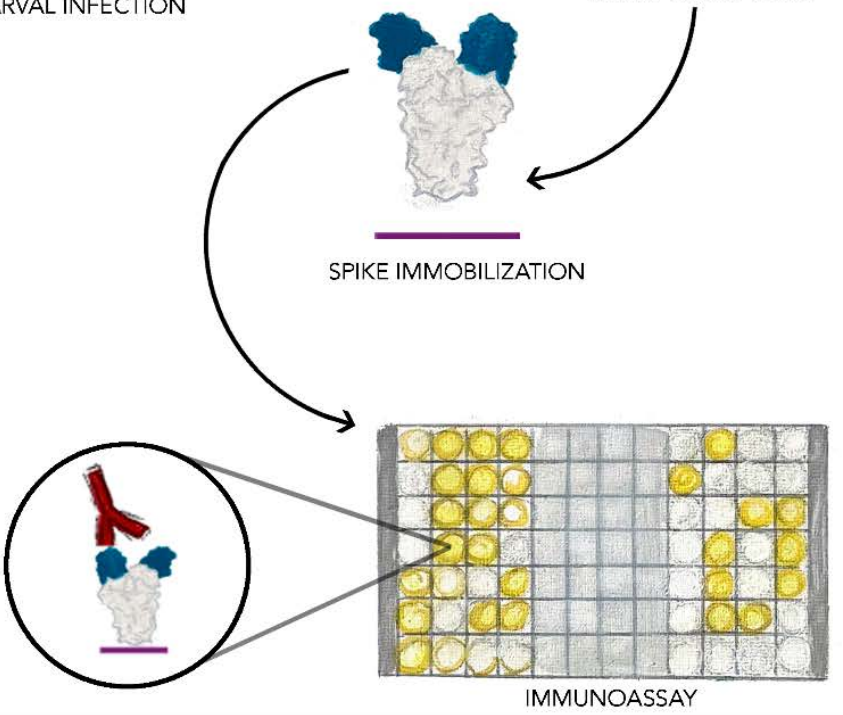

A rapid and cost-effective process for scale-up the production of SARS-CoV-2 Spike protein was developed in this work. The authors obtained high quality protein (trimeric and glycosylated state) after one step of purification from R. nu larvae. Our results demonstrate that the Spike protein produced in insect larvae is immunoreactive against the sera from COVID-19 patients and can be used as single antigen in immunoassays for the detection of anti-SARS-Cov-2 antibodies

Keywords: SARS-CoV-2 coronavirus, insect larvae, trimeric spike, antibodies, ELISA

\section{Introduction}

The outbreak of a new virus, SARS-CoV-2, in December 2019 has had a serious impact on human health (Zhu et al., 2020). The severe acute respiratory syndrome related to this virus, officially designated COVID-19, has rapidly spread all over the world, progressing into a pandemic. This situation has urgently impelled many companies and public research institutes to concentrate their efforts on the search for effective vaccines, therapeutics, and diagnostic tests. 
SARS-CoV-2 is a single-stranded RNA-enveloped virus. The coronavirus spike (S) glycoprotein is surface-exposed in a large number of copies, and it mediates entry into host cells by interacting with angiotensin-converting enzyme 2 (ACE2) (Ke et al., 2020). For these reasons, S protein rapidly became the main target of neutralizing antibodies and the focus of therapeutic and vaccine design (Salvatori et al., 2020). In virions, the S protein exists as a large (over $500 \mathrm{kDa}$ ), highly glycosylated homotrimer, each monomer consisting of a globular head, the S1 subunit with its receptor-binding domain (RBD), and the S2 subunit, containing the protein-machinery that mediates viral-cell membrane fusion. The S protein normally exists in a metastable, prefusion conformation, but once the virus interacts with the host cell, an extensive rearrangement occurs, allowing the virus to fuse with the host cell membrane. The spikes are coated with polysaccharide molecules to camouflage themselves, evading surveillance by the host immune system during entry (Watanabe et al., 2020).

Studies conducted in COVID 19 patients have reported that S and nucleocapsid (NCP) proteins are the main SARS-CoV-2 antibody targets (Burbelo et al., 2020). These antibodies are detectable from approximately 6 days after PCR confirmation of infection. It was demonstrated that those antibodies directed against RBD into S show a neutralizing capacity and, hence, can prevent infection (Seydoux et al., 2020; Suthar et al., 2020).

Serological tests for COVID-19 are based on the detection of multiple targets of the virus, including S, RBD, NCP, and non-structural proteins, and are extensively used to identify whether people have been exposed to SARS-CoV-2 by looking at their immune response (Ghaffari et al., 2020). During the pandemic, many efforts have been directed towards detecting, tracking, and better understanding human humoral responses to SARS-CoV-2 infection. It is crucial to develop robust and reliable serological assays to study the antibody kinetics and neutralization efficiency and monitor reinfections with genetic variants and new virus strains, in particular, the duration of antibodies in virus-exposed individuals and vaccine-mediated immunity. Currently, the RBD and 
S proteins are the most reliable antigens for measuring the abundance of neutralizing antibodies (Galipeau et al., 2020).

Different strategies were described to obtain the S protein by biotechnological methods. Because of the structural complexity and post-translational modifications of the S protein, major efforts were directed to mammalian cell culture as a suitable productive system (Stuible et al., 2021). As already described, the $\mathrm{S}$ protein is a large homotrimer with $22 \mathrm{~N}$-linked glycosylation sites per monomer (Watanabe et al., 2020). As a consequence of its structural complexity, it is not surprising systems like Chinese hamster ovary (CHO) and human embryonic kidney (HEK) render low yields in mammalian (Esposito et al., 2020; Walls et al., 2020). Moreover, the great volume of culture media needed for S expression in mammalian cultures at a high scale is too expensive, especially to obtain this antigen for serological assays.

We previously exhaustively studied the use of insect larvae such as Rachiplusia nu, an important agronomic plague in America, as a platform to produce different proteins in a short time and at a low cost (M. Targovnik et al., 2016). Also, we previously identified and described the chromatographic behavior of the main contaminant proteins present in the host to facilitate the downstream processing of any recombinant protein produced in this system (Mc Callum et al., 2019).

Here we established a rapid and cost-effective process for the expression and purification of a high-quality trimeric version of SARS-CoV-2 S protein by using the baculovirus-insect larvae system. This novel recombinant protein was used for developing a new serological ELISA test for COVID-19, showing high sensitivity and specificity with low operational complexity and cost.

\section{Materials and methods}

\section{Recombinant virus construction}

This article is protected by copyright. All rights reserved. 
We based our studies on a previously described version of SARS-CoV-2 S protein sequence, stabilized in its prefusion conformation (Wrapp et al., 2020). Briefly, the expressed protein was expected to include the ectodomain (residues 19-1207) of the SARS-CoV-2 Wuhan-Hu-1 S protein (GenBank: QHD43416.1) without native signal peptide, where the furin cleavage site (residues 682-685, PRRA) was removed (GSAS mutations) and residues at positions 986 (K) and 987(V) were mutated to proline; additionally, a C-terminal T4 fibritin trimerization domain, a TEV protease cleavage site, and a histidine tag were included (Figure 1). For secretion, S protein was expressed under gp64 baculoviral signal peptide. The DNA sequence was codon-optimized for baculovirus expression and chemically synthesized (Genscript, Piscataway, NJ, USA). The S sequence and the enhanced green fluorescent protein (EGFP) cDNA were cloned into the pFastBacDual vector (Thermo Fisher Scientific, Waltham, USA) under the polyhedrin (polh) and p10 promoter, respectively, for expression in the baculovirus system. For this purpose, the EGFP (GenBank Accession No. NC_013179.1) was cloned into SmaI and Nco1 sites of the pFastBacDual vector (Targovnik et al., 2019)]. Then, the S cassette was subcloned into the pFastBacDual Vector into BamH1 and HindIII sites to generate the pFBD-p10-EGFP-polh-S construction.

The recombinant baculoviruses were obtained using the Bac to Bac ${ }^{\circledR}$ baculovirus expression system (Thermo Fisher Scientific, USA), following the manufacturer's instructions. The pFBDp10-EGFP-polh-S vector was transformed into a chemically competent E. coli DH10Bac ${ }^{\mathrm{TM}}$ strain (Thermo Fisher Scientific, USA) by heat shock to generate the recombinant bacmid by transposition. Then, the bacmids were purified and used to transfect 1 million Sf9 cells using Cellfectin II Reagent (Thermo Fisher Scientific, USA). After 4-day incubation at $27{ }^{\circ} \mathrm{C}$, the cell culture supernatant was collected and centrifuged at $500 \times \mathrm{g}$ for $10 \mathrm{~min}$. The transfection efficiency was determined by measuring EGFP expression by fluorescence under UV light. The recombinant Autographa californica nuclear polyhedrosis virus (AcMNPV) polyhedrin-minus

This article is protected by copyright. All rights reserved. 
virus containing EGFP under the control of the p10 promoter and the S sequence under the control of the polyhedrin promoter was named rAcMNPV-S. Then, a round of amplification was performed in Sf9 cells seeded in T-25 flasks at $27^{\circ} \mathrm{C}$, at a low multiplicity of infection (MOI) of 0.02. The Sf900 II insect cell culture medium and the antibiotic and antimycotic solutions were from InvitrogenTM (Gaithersburg, MD, USA) and the fetal bovine serum (FBS) was from Nutrientes Naturales S.A. (Buenos Aires, Argentina). The amplified rAcMNPV-S was titrated by plaque assay (O’Reilly DR, Miller LK, 1994). This high-titer rAcMNPV-S was the viral stock used for protein production in insect larvae.

\section{Expression of S protein in insect larvae}

R. nu larvae were from Agldea (Pergamino, Argentina). They were reared in trays at $23-25{ }^{\circ} \mathrm{C}$ in a $70 \%$ humidified chamber, with a 16:8 light:dark photoperiod, and fed a high wheat-germ diet until they reached their fifth instar (20 days of age) prepared by Agldea (Pergamino, Argentina). For all the experiments, batches of 500 fifth-instar larvae were injected with $50 \mu \mathrm{L}$ of the recombinant baculovirus stock (diluted to $1 \times 10^{7} \mathrm{PFU} \mathrm{mL}-1$ ) near the third prolegs, as shown in Figure 2. To characterize and quantify the recombinant protein produced, larvae that were alive and fluorescent under UV light were harvested at day 4 post-infection and frozen immediately at $-80^{\circ} \mathrm{C}$ until they were processed for analysis. Larvae infected with a non-related recombinant baculovirus were included as the control.

\section{Recombinant S protein purification by Immobilized Metal-Ion Affinity Chromatography (IMAC)}

In a typical process, $75 \mathrm{~g}$ of infected larvae were homogenized directly with $200 \mathrm{ml}$ of equilibration buffer containing $10 \mathrm{mg}$ glutathione crystals, $50 \mathrm{mM}$ arginine, and $4 \mathrm{mM}$ PMSF and 1/200 (V/V) protease inhibitor cocktail (Sigma-Aldrich, Saint Louis, MO, USA) using a Bag Mixer 400 homogenizer (Interscience, Saint-Nom-la-Bretèche, France). Then, the larval extract was

This article is protected by copyright. All rights reserved. 
centrifuged at $10,000 \times \mathrm{g}$ for $30 \mathrm{~min}$ at $4{ }^{\circ} \mathrm{C}$ and the pellet was discarded. The supernatant was filtered through Whatman paper using a filter holder with a receptor (Nalgene, USA) to remove the lipid fraction remaining at the top. The filtered sample was centrifuged for a second time in the same conditions, and the supernatant was filtered through $3 \mu \mathrm{m}$ (Sartopore o SartoBran capsules). Then, two experiments were conducted. In the first experiment, the clarified homogenate was loaded into the HisTrap FF 5 ml column (Cytiva, Marlborough, USA) previously equilibrated with 10CV (column volume) of $20 \mathrm{mM}$ phosphate buffer, pH 7.4, $20 \mathrm{mM}$ imidazole, $300 \mathrm{mM} \mathrm{NaCl}$, and $50 \mathrm{mM}$ arginine, and washed with 10CV of the same buffer. The recombinant protein was eluted with a buffer containing $500 \mathrm{mM}$ imidazole, $100 \mathrm{mM}$ arginine, and $10 \%$ glycerol. In the second experiment, the same chromatography was done but the matrix was equilibrated with the same buffer containing $20 \mathrm{mM}$ imidazole, a second wash was done with 80 $\mathrm{mM}$ imidazole, and then the $\mathrm{S}$ protein was eluted with $500 \mathrm{mM}$ imidazole. After that, an optimized protocol consisted in equilibrating the chromatographic matrix directly with the same buffer containing $80 \mathrm{mM}$ imidazole, and after washing, the S protein was eluted by adding 500 $\mathrm{mM}$ imidazole. In all cases, the linear flow rate was $0.4 \mathrm{~cm}$ min-1, and all fractions were collected and subjected to SDS-PAGE and Western blot analysis.

\section{Determination of protein concentration}

Total protein concentration was determined by the Bradford microassay protocol (Bradford, 1976) using the Quick Start ${ }^{\mathrm{TM}}$ Bradford reagent (BioRad, Hercules, CA, USA). The samples used were crude larval extract and the purified S fraction. Additionally, the concentration of purified S protein was determined in an SDS-PAGE image with a diluted series of control bovine serum albumin.

\section{SDS-PAGE and Western Blot analysis}

This article is protected by copyright. All rights reserved. 
Larval extracts and purification fractions were resolved by SDS-PAGE (10\% polyacrylamide gels). Before loading the samples into the wells, they were heated for $5 \mathrm{~min}$ at $100^{\circ} \mathrm{C}$ in sample buffer (125 mM Tris-HCl, pH 6.8, 4\% [w/v] SDS, 20\% [w/v] glycerol, 0.01\% [w/v] bromophenol blue, and $10 \%[\mathrm{v} / \mathrm{v}] 2$-mercaptoethanol). One of the lanes was reserved for the protein marker to determine the MW of the protein bands. The resulting gels were either stained with Coomassie Blue R-250 or transferred onto nitrocellulose membranes (Cytiva, Marlborough, USA). Membranes were then incubated overnight at $4{ }^{\circ} \mathrm{C}$ in blocking solution (phosphate-buffered saline $[\mathrm{PBS}]-3 \%$ skim milk [PBS-M]). After a 10 -min wash with PBS containing $0.05 \% \mathrm{v} / \mathrm{v}$ Tween 20 (PBS-T), the membrane was incubated for $2 \mathrm{~h}$ with mouse anti-His antibody (BD Biosciences, USA) $1 / 2,500$ in $0.05 \%$ PBS-T-1\% skim milk, and then washed three times with PBS-T. Polyclonal rabbit anti-mouse immunoglobulin conjugated with $\operatorname{HRP}(1 / 30,000$ in $0.05 \%$ PBS-T-1\% skim milk) was used as the secondary antibody. Development was carried out with 3,3'-diaminobenzidine (DAB) (Sigma-Aldrich, USA) staining or, alternatively, with an enhanced chemiluminescent substrate (ECL) and high-performance chemiluminescence films (CL-X Posure ${ }^{\mathrm{TM}}$, Thermo Fisher Scientific, USA).

\section{Characterization of the recombinant S protein expressed in $R . n u$}

\section{Size exclusion chromatography}

The oligomerization state of the recombinant S protein was evaluated by high-resolution size exclusion chromatography (SEC). Elution fractions from IMAC containing purified S protein were collected and concentrated, and the buffer was exchanged and loaded on a Superdex 200 increase 10/300 (Cytiva, Marlborough, USA) equilibrated in 100 mM sodium phosphate buffer, $150 \mathrm{mM} \mathrm{NaCl}, \mathrm{pH}$ 7.4. All fractions were collected, and the S protein was revealed by WB using

an anti-6x His-tag antibody, as described previously. The calculated molecular weight (MW) of the expressed protein, without considering the glycan moieties, was 138914 Da.

This article is protected by copyright. All rights reserved. 


\section{Sera collection}

\section{Healthy control individuals}

Control serum/plasma $(n=83)$ was obtained from samples collected from healthy individuals before the outbreak of SARS-CoV-2. The sample collection was approved by the Ethics Committee of José de San Martín Clinical Hospital, University of Buenos Aires (UBA), Buenos Aires, Argentina. Sera were stored at $-20^{\circ} \mathrm{C}$ until assayed.

\section{COVID-19 patients}

Serum/plasma samples were collected from a total of 98 COVID-19 cases confirmed to be infected with SARS-CoV-2 by real-time RT-PCR (rRT-PCR) on samples from the respiratory tract. These samples were provided by the Biobank of Infectious Diseases (BBEI) of the Institute for Biomedical Research on Retroviruses and AIDS (INBIRS). Seventy-eight of these samples were IgG positive and 20 were IgG negative for SARS-CoV-2 by COVIDAR IgG ELISA test (Laboratorio Lemos S.R.L., Argentina). Sample collection and protocols were approved by the Ethics Committee of BBEI-INBIRS and the Ethics Committee in Clinical Research of the School of Pharmacy and Biochemistry, UBA. All subjects were informed about the purpose of the study, and they signed consent for study participation. Sera were stored at $-20^{\circ} \mathrm{C}$ until assayed.

\section{Spike application in an immunoassay for antibodies for SARS-CoV-2 assessment}

\section{Reagents}

PBS was used as the microplate coating buffer. PBS-M and PBS-T were used as blocking solution and washing buffer, respectively. Sample or reagent dilutions were prepared in $3 \% \mathrm{w} / \mathrm{v}$ skim milk, 0.05 \% v/v Tween 20 in PBS (PBS-MT). Streptavidin-Horseradish Peroxidase (HRP) and rabbit anti-human IgG-biotin were purchased from Jackson ImmunoResearch Laboratories, Inc. (USA). The 3,3',5,5'-tetramethyl-benzidine/ $\mathrm{H}_{2} \mathrm{O}_{2}$ (Single Component TMB Peroxidase EIA

This article is protected by copyright. All rights reserved. 
Substrate Kit, BioRad, Hercules, CA, USA) was employed as the chromogenic substrate. Except when otherwise indicated, incubations were performed at RT, washing steps were performed with PBS-T, and $50 \mu \mathrm{L}$ per well were added in each incubation step.

\section{ELISA with colorimetric detection}

Polystyrene microplates (Maxisorp, NUNC, Roskilde, Denmark) were coated overnight at $4{ }^{\circ} \mathrm{C}$ with $0.1 \mu \mathrm{g}$ purified Spike per well, in coating buffer, and washed five times with PBS. Blocking solution $(200 \mu \mathrm{L} /$ well $)$ was added, and plates were incubated for $1 \mathrm{~h}$. After washing six times, duplicate serum samples diluted 1/100 (100 $\mu \mathrm{L} /$ well) were added and incubated for $1 \mathrm{~h}$. Microplates were washed six times and incubated for 30 min at $37{ }^{\circ} \mathrm{C}$ with anti-human IgG-biotin (diluted 1/180,000). Plates were washed six times, and bound antibodies were detected with Streptavidin-HRP (diluted 1/2,000, 30 min at $37^{\circ} \mathrm{C}$ ). After washing (five times plus one final wash with PBS), the chromogenic substrate was added and plates were incubated for 15 min in the dark. The color reaction was stopped with $2 \mathrm{M} \mathrm{H}_{2} \mathrm{SO}_{4}$. The oxidized substrate was measured at $450 \mathrm{~nm}$ with an ELISA plate reader MultiskanFC (Thermo Scientific Labsystems, USA). The blank control was made by replacing serum samples with PBS-MT. Results were calculated as specific absorbance $(\mathrm{A}=$ the mean of each sample minus the mean of the blank control) and expressed as Standard Deviation scores: SDs $=(\mathrm{A}-\mathrm{Ac}) / \mathrm{SDc}$, where Ac is the mean specific absorbance of healthy control sera and SDc its standard deviation. The cut-off value of the assay was set at SDs $=3.0$.

\section{Statistical analysis}

The normal distribution of data was analyzed by the D'Agostino and Pearson omnibus normality test. To remove outliers from normally distributed healthy control individuals, the Rout test was

performed. The selection of optimal cut-off values was based on curves constructed by plotting the calculated specificity and sensitivity vs. the corresponding cut-off values. Statistical 
significance was evaluated using either parametric tests: paired-samples Student t-test and unpaired-samples Student t-test with Welch correction, or non-parametric tests: Wilcoxon matched-pairs signed-rank test or Mann-Whitney U-test for unpaired data, when applicable. Calculations were performed using GraphPad Prism version 6.01 for Windows (GraphPad Software, San Diego California, USA, www.graphpad.com). A p-value $<0.05$ was considered statistically significant.

\section{Result and Discussion}

\section{Expression and purification of the recombinant spike in insect larvae}

A low-cost alternative to cell culture-based protein production is the use of live insect larvae as "mini bioreactors". To obtain the recombinant version of the S protein, we cloned the expression cassette into the pFastBacDualGFP vector under the control of the strong baculovirus polyhedrin promoter. The expression cassette included gp64 signal peptide, which targets the recombinant protein to the secretion pathway. After transfection and amplification in Sf9 insect cells, a recombinant baculovirus seed-stock for expression in larvae was obtained. Insect larvae support many of the post-translational modifications that enable proteins to achieve their biologically functional native conformation (Loustau et al., 2008).

$R$. nu larvae were infected by injection of the baculovirus by intrahemocele injection with approximately $5 \times 10^{5}$ pfu of viral stock (Figure 2a-b). From our experience, this dose was the best option to achieve a high level of S protein expression and no larval mortality. The larvae infected with the recombinant baculovirus expressed, in addition to the proteins of interest, the EGFP protein, which allowed us to determine the optimum day of harvest by observation under UV light. At 4 day post infection (dpi), the fluorescence was maximal, and then the viability of the larvae decreased significantly. Therefore, the larvae were harvested at 4 dpi under a UV lamp using fluorescence as an indicator of infection. We proceeded to obtain the clarified homogenate

This article is protected by copyright. All rights reserved. 
from the larvae and purify the recombinant proteins expressed in insect larvae $R$. nu by IMAC. The gp64 signal peptide was effective to target $S$ protein to the secretory pathway. The recombinant S protein was secreted to hemolymph and this localization made it easier to extract it from the larvae.

SDS-PAGE revealed that most of the proteins of the crude extract were removed in the passthrough fraction during purification by IMAC when the sample was loaded without imidazole. However, when the bound material, containing the protein of interest, was desorbed after a single $500 \mathrm{mM}$ imidazole step, an important contaminant of hemolymph (hexamerin, 76 $\mathrm{kDa}$ approx.) was still present in the elution fraction. After some rounds of optimization, we concluded that when the extracts were run directly on the chromatographic matrix previously equilibrated with $20 \mathrm{mM}$ imidazole, most contaminants, including hexamerin, eluted in the passthrough or washing fractions, while the recombinant S protein remained bound to the matrix. Nevertheless, in this condition, another contaminant with a molecular weight similar to that of the S protein was present and eluted with $80 \mathrm{mM}$ imidazole (Figure 3). For these reasons, we assessed a new protocol, which directly equilibrated the matrix with the same buffer containing $80 \mathrm{mM}$ imidazole. As judged by reducing SDS-PAGE and WB, the estimated molecular weight of the recombinant $\mathrm{S}$ protein was $150 \mathrm{kDa}$ (monomer), indicating that it was correctly glycosylated and did not suffer protease degradation (Figure 3). Other authors have expressed the ectodomain of S protein with the native peptide sequence in hemolymph of Bombyx mori larvae and reported that recombinant protein was cleaved probably by a host furin-protease. In the same work, the authors resolved it with a version of S protein modified in furin protease-target site (Fujita et al., 2020). In the present work, we decided to synthesize a version of S protein where the furin cleavage site (residues 682-685, PRRA) was removed because furin protease activity was only described in Spodoptera frugiperda, a $R$. nu related species (Westenberg et al., 2002).

This article is protected by copyright. All rights reserved. 
The amount of recombinant S protein was $15 \mathrm{ug} / \mathrm{g}$ of larvae at 4 dpi on our platform based on $R$. nu. The process based on Bombyx mori previously reported by other authors (Fujita et al., 2020) can be compared with ours as follows: in both cases, the optimal day of S protein harvest was 4 dpi after larval infection; however, in Bombyx mori, it was necessary to extract the whole hemolymph of each larva for purification while, in our case, a complete extract was done with all infected larvae, thus simplifying the biotechnological process. In B. mori, the estimated value of the purified S protein from $10 \mathrm{ml}$ hemolymph (35 larvae) was $100 \mu \mathrm{g}$, and the same yield was obtained with $45 R$. nu larvae in the process herein described.

\section{Protein quality assessment}

We assessed whether insect larvae-produced SARS CoV-2 S protein was suitable for our intended use. The trimetric nature of the S protein, which is typical of Type I viral fusion proteins, is a critical quality attribute of recombinant S proteins in different expression systems (Esposito et al., 2020). We evaluated the oligomeric state of the IMAC-purified S protein from $R$. nu larvae by size exclusion chromatography (SEC) in a Superdex 200 column. Figure 4a shows a typical SEC chromatogram of the larvae-expressed SARS CoV-2 S protein eluting as a broad peak with an elution volume close to $10 \mathrm{ml}$, compatible with a 450-500 $\mathrm{kDa}$ protein, in good accordance with the expected trimeric nature of the purified protein. The $\mathrm{S}$ monomer is a protein with an apparent molecular weight of $\sim 150 \mathrm{kDa}$ bearing many glycan moieties, which affects its hydrodynamic behavior (the MW calculated from the amino acid sequence is $138 \mathrm{kDa}$ ). The presence of $\mathrm{S}$ protein in these fractions was confirmed by WB, using an anti 6xHis tag-specific antibody (Figure 4b). Notably, two peaks, denoted as peak \#1 and \#2, were also observed. However, these peaks were not recognized by the anti 6xHis tag antibody in the WB revealed with ECL (Figure 4b), indicating that they might correspond to non-related impurities or to a dissociated and fragmented S protein with its carboxyl-terminal cleaved. It should be noted that

This article is protected by copyright. All rights reserved. 
some proteolysis can occur during concentration and buffer exchange of the sample performed before injecting on a SEC column.

\section{SPIKE application in an immunoassay for antibodies for SARS-CoV-2 assessment}

The immunochemical behavior of the recombinant version of the S protein expressed in insect larvae $R$. nu was evaluated during the following use as an immobilized antigen in the development of an indirect ELISA aimed at detecting the presence of anti-S specific IgG antibodies in human serum/plasma samples. After an initial round of optimization (antigen concentration and binding conditions, primary and secondary antibodies dilution, washing steps), a panel of 83 human control serum/plasma and 98 COVID-19 patients' serum/plasma were analyzed. To calculate the coefficient variation, a positive serum from a COVID-19 patient was employed. The intra-assay coefficient variation was 3.21\% $(\mathrm{n}=2)$ and the inter-assay coefficient variation was $20.11 \%(n=4)$. The test performance was optimized in terms of sensitivity and specificity by evaluating the effect of different cut-off values (in SDs) on receiver operating characteristic curves (ROC) (Figure 5). The area under the ROC curve (AUC) was 0.893, indicating that the method had high accuracy to distinguish between samples from the two groups under study (Carter et al., 2016). When a cut-off value of 3.0 SDs was established, 75 out of 78 COVID-19 samples that tested positive by COVIDAR IgG ELISA Test, were also positive by our developed ELISA (sensitivity: 96.2\%). The specificity, calculated as 100\% minus the percentage of true negative samples (normal human sera, $\mathrm{n}=83$ ) detected as positive, was $98.8 \%$. The median SDs range of true negative samples was -0.22 (range: -1.78 to 3.21 ) and the median SDs range of true positive samples was 7.32 (range: 0.00 to 23.20). Moreover, the concordance between the ELISA developed herein and the COVIDAR IgG ELISA test was 95.96\%, with a kappa statistic of 0.879 , representing a substantial agreement between the two methods. The results presented in the present work demonstrate that the Spike protein produced in insect larvae is immunoreactive against the sera from COVID-19 patients and can be used in immunoassays

This article is protected by copyright. All rights reserved. 
for the detection of anti-SARS-Cov-2 antibodies (Figure 6). The strategy reported herein should be accessible to many laboratories and should allow the easy production of Spike. In turn, the availability of properly folded Spike would encourage researchers to improve current and develop new immunochemical tests for anti-SARS-Cov-2 antibodies detection.

On the other hand, it is known that cellular immune response to SARS-CoV-2 is critical in controlling disease. For this reason it is important to analyze the magnitude and phenotype of the SARS-CoV-2-specific T cell response. For this purpose different authors have employed peptide pools from a range of viral proteins, including spike, nucleoprotein and membrane protein (Zuo et al., 2021). Additionally, other authors have evaluated T-cells proliferation after stimulation with these proteins (Avendaño-Ortiz et al., 2020). In view of that, S protein produced in insect larvae could be also employed for this purpose.

\section{Conclusions}

In this work, we show that SARS-CoV-2 recombinant S protein could be produced inexpensively after infection of $R$. nu larvae and easily purified later after a single chromatographic step. Noteworthy, the antigenic properties of this large, complex, highly glycosylated protein are retained, as evidenced during its application for developing a serologic ELISA test. One gram of insect larvae produces an amount of S protein sufficient for 150 determinations in the ELISA method. The scale-up of S protein production is linear in this biotechnological platform, avoiding the use of complex equipment like bioreactors. Thus, it is straightforward to conclude that our approach represents a rapid, easy, and cost-effective method for the production of recombinant S for diagnostic applications. We expect that our approach will bring new tools for serologic test producers to face the unprecedented demand for these products during the current COVID 19 pandemic.

\section{Ethical statement}

This article is protected by copyright. All rights reserved. 
The authors declare no conflict of interest.

\section{Declaration of competing interests}

The authors declare that they have no known competing financial interests or personal relationships that could have appeared to influence the work reported in this paper.

Acknowledgments: Authors are thankful to Dra Lucia Vicenta Cavallaro for support on virology aspects related to COVID-19. We are also grateful to Biobanco de Enfermedades Infecciosas Colección COVID19 working group: Yesica Longueira, Horacio Salomon and Gabriela Turk for collecting and providing the sera. This work was supported by the Agencia Nacional de Promoción de la Investigación, el Desarrollo Tecnológico y la Innovación (ANPCyT) (IPCOVID-19-209). SSB, AT, SCV, MGL, OT, AMT, FJW, LGA, MF, SNV and MVM are career researchers of the Consejo Nacional de Investigaciones Científicas y Técnicas de Argentina (CONICET). IS, GJMC, JMB, JMM are research fellows of CONICET. ABS is research fellow of UBA. JIM is research fellow of ANPCyT.

\section{Data availability statement}

The data that support the findings of this study are available from the corresponding author upon reasonable request.

\section{References}

Avendaño-Ortiz, J., Lozano-Rodríguez, R., Martín-Quirós, A., Maroun-Eid, C., Terrón, V., Valentín, J., Montalbán-Hernández, K., Ruiz de la Bastida, F., García-Garrido, M. A., Cubillos-Zapata, C., del Balzo-Castillo, Á., Aguirre, L. A., \& López-Collazo, E. (2020). Proteins from SARS-CoV2 reduce T cell proliferation: A mirror image of sepsis. Heliyon, 6(12), 0-7. doi:

10.1016/j.heliyon.2020.e05635

This article is protected by copyright. All rights reserved. 
Bradford. (1976). A rapid and sensitive method for the quantitation of microgram quantities of protein utilizin the principle of protein-dye binding. Anal Biochem, 72, 248-254.

Burbelo, P. D., Riedo, F. X., Morishima, C., Rawlings, S., Smith, D., Das, S., Strich, J. R., Chertow, D. S., Davey, R. T., \& Cohen, J. I. (2020). Sensitivity in detection of antibodies to nucleocapsid and spike proteins of severe acute respiratory syndrome coronavirus 2 in patients with coronavirus disease 2019. Journal of Infectious Diseases, 222, 206-213. doi: 10.1093/infdis/jiaa273

Carter, J. V., Pan, J., Rai, S. N., \& Galandiuk, S. (2016). ROC-ing along: Evaluation and interpretation of receiver operating characteristic curves. Surgery (United States), 159(6), 1638-1645. doi: 10.1016/j.surg.2015.12.029

Esposito, D., Mehalko, J., Drew, M., Snead, K., Wall, V., Taylor, T., Frank, P., Denson, J. P., Hong, M., Gulten, G., Sadtler, K., Messing, S., \& Gillette, W. (2020). Optimizing high-yield production of SARS-CoV-2 soluble spike trimers for serology assays. Protein Expression and Purification, 174(May), 105686. doi: 10.1016/j.pep.2020.105686

Fujita, R., Hino, M., Ebihara, T., Nagasato, T., Masuda, A., Lee, J. M., Fujii, T., Mon, H., Kakino, K., Nagai, R., Tanaka, M., Tonooka, Y., Moriyama, T., \& Kusakabe, T. (2020). Efficient production of recombinant SARS-CoV-2 spike protein using the baculovirus-silkworm system. Biochemical and Biophysical Research Communications, 529(2), 257-262. doi: 10.1016/j.bbrc.2020.06.020

Galipeau, Y., Greig, M., Liu, G., Driedger, M., \& Langlois, M. A. (2020). Humoral Responses and Serological Assays in SARS-CoV-2 Infections. Frontiers in Immunology, 11(December), 1-19. doi: $10.3389 /$ fimmu.2020.610688

This article is protected by copyright. All rights reserved. 
Ghaffari, A., Meurant, R., \& Ardakani, A. (2020). COVID-19 serological tests: how well do they actually perform? Diagnostics, 10(7), 1-14. doi: 10.3390/diagnostics10070453

Ke, Z., Oton, J., Qu, K., Cortese, M., Zila, V., McKeane, L., Nakane, T., Zivanov, J., Neufeldt, C. J., Cerikan, B., Lu, J. M., Peukes, J., Xiong, X., Kräusslich, H. G., Scheres, S. H. W., Bartenschlager, R., \& Briggs, J. A. G. (2020). Structures and distributions of SARS-CoV-2 spike proteins on intact virions. Nature, 588(7838), 498-502. doi: 10.1038/s41586-020$2665-2$

Loustau, M. N., Romero, L. V., Levin, G. J., Magri, M. L., López, M. G., Taboga, O., Cascone, O., \& Miranda, M. V. (2008). Expression and purification of horseradish peroxidase in insect larvae. Process Biochemistry, 43(1), 103-107. doi: 10.1016/j.procbio.2007.10.011

M. Targovnik, A., B. Arregui, M., F. Bracco, L., Urtasun, N., F. Baieli, M., M. Segura, M., A. Simonella, M., Fogar, M., J. Wolman, F., Cascone, O., \& V. Miranda, M. (2016). Insect Larvae: A New Platform to Produce Commercial Recombinant Proteins. Current Pharmaceutical Biotechnology, 17(5), 431-438. doi: 10.2174/138920101705160303163947

Mc Callum, G. J., Arregui, M. B., Smith, I., Bracco, L. F., Wolman, F., Cascone, O., Targovnik, A. M., \& Miranda, M. V. (2019). Recombinant protein purification in baculovirus-infected Rachiplusia nu larvae: An approach towards a rational design of downstream processing strategies based on chromatographic behavior of proteins. Protein Expression and Purification, 158(January), 44-50. doi: 10.1016/j.pep.2019.02.009

O’Reilly DR, Miller LK, L. V. (1994). Baculovirus expression vector:a laboratory manual. Oxford: Oxford University Press.

Salvatori, G., Luberto, L., Maffei, M., Aurisicchio, L., Aurisicchio, L., Roscilli, G., Roscilli, G.,

This article is protected by copyright. All rights reserved. 
Palombo, F., Marra, E., \& Marra, E. (2020). SARS-CoV-2 spike protein: An optimal immunological target for vaccines. Journal of Translational Medicine, 18(1), 1-3. doi: $10.1186 / s 12967-020-02392-y$

Seydoux, E., Homad, L. J., MacCamy, A. J., Parks, K. R., Hurlburt, N. K., Jennewein, M. F., Akins, N. R., Stuart, A. B., Wan, Y. H., Feng, J., Whaley, R. E., Singh, S., Boeckh, M., Cohen, K. W., McElrath, M. J., Englund, J. A., Chu, H. Y., Pancera, M., McGuire, A. T., \& Stamatatos, L. (2020). Analysis of a SARS-CoV-2-Infected Individual Reveals Development of Potent Neutralizing Antibodies with Limited Somatic Mutation. Immunity, 53(1), 98-105.e5. doi: 10.1016/j.immuni.2020.06.001

Stuible, M., Gervais, C., Lord-Dufour, S., Perret, S., L’Abbé, D., Schrag, J., St-Laurent, G., \& Durocher, Y. (2021). Rapid, high-yield production of full-length SARS-CoV-2 spike ectodomain by transient gene expression in CHO cells. Journal of Biotechnology, 326, 2127. doi: $10.1016 / j . j b i o t e c .2020 .12 .005$

Suthar, M. S., Zimmerman, M. G., Kauffman, R. C., Mantus, G., Linderman, S. L., Hudson, W. H., Vanderheiden, A., Nyhoff, L., Davis, C. W., Adekunle, O., Affer, M., Sherman, M., Reynolds, S., Verkerke, H. P., Alter, D. N., Guarner, J., Bryksin, J., Horwath, M. C., Arthur, C. M., ... Wrammert, J. (2020). Rapid Generation of Neutralizing Antibody Responses in COVID-19 Patients. Cell Reports Medicine, 1(3), 100040. doi: 10.1016/j.xcrm.2020.100040

Targovnik, A. M., Ferrari, A., Mc Callum, G. J., Arregui, M. B., Smith, I., Bracco, L. F., Alfonso, V., López, M. G., Martínez-Solís, M., Herrero, S., \& Miranda, M. V. (2019). Highly efficient production of rabies virus glycoprotein G ectodomain in Sf9 insect cells. 3 Biotech, 9(11), 1-11. doi: 10.1007/s13205-019-1920-4

Walls, A. C., Park, Y. J., Tortorici, M. A., Wall, A., McGuire, A. T., \& Veesler, D. (2020). Erratum:

This article is protected by copyright. All rights reserved. 
Structure, Function, and Antigenicity of the SARS-CoV-2 Spike Glycoprotein (Cell (2020) 181(2) (281-292.e6), (S0092867420302622), (10.1016/j.cell.2020.02.058)). Cell, 183(6), 1735. doi: 10.1016/j.cell.2020.11.032

Watanabe, Y., Allen, J. D., Wrapp, D., McLellan, J. S., \& Crispin, M. (2020). Site-specific glycan analysis of the SARS-CoV-2 spike. Science, 369(6501), 330-333. doi: 10.1126/science.abb9983

Westenberg, M., Wang, H., IJkel, W. F. J., Goldbach, R. W., Vlak, J. M., \& Zuidema, D. (2002). Furin Is Involved in Baculovirus Envelope Fusion Protein Activation. Journal of Virology, 76(1), 178-184. doi: 10.1128/jvi.76.1.178-184.2002

Wrapp, D., Wang, N., Corbett, K. S., Goldsmith, J. A., Hsieh, C. L., Abiona, O., Graham, B. S., \& McLellan, J. S. (2020). Cryo-EM structure of the 2019-nCoV spike in the prefusion conformation. Science, 367(6483), 1260-1263. doi: 10.1126/science.aax0902

Zhu, N., Zhang, D., Wang, W., Li, X., Yang, B., Song, J., Zhao, X., Huang, B., Shi, W., Lu, R., Niu, P., Zhan, F., Ma, X., Wang, D., Xu, W., Wu, G., Gao, G. F., \& Tan, W. (2020). A Novel Coronavirus from Patients with Pneumonia in China, 2019. New England Journal of Medicine, 382(8), 727-733. doi: 10.1056/nejmoa2001017

Avendaño-Ortiz, J., Lozano-Rodríguez, R., Martín-Quirós, A., Maroun-Eid, C., Terrón, V., Valentín, J., Montalbán-Hernández, K., Ruiz de la Bastida, F., García-Garrido, M. A., Cubillos-Zapata, C., del Balzo-Castillo, Á., Aguirre, L. A., \& López-Collazo, E. (2020). Proteins from SARS-CoV2 reduce T cell proliferation: A mirror image of sepsis. Heliyon, 6(12), 0-7. doi: 10.1016/j.heliyon.2020.e05635

Zuo, J., Dowell, A. C., Pearce, H., Verma, K., Long, H. M., Begum, J., Aiano, F., Amin-Chowdhury,

This article is protected by copyright. All rights reserved. 
Z., Hallis, B., Stapley, L., Borrow, R., Linley, E., Ahmad, S., Parker, B., Horsley, A.,

Amirthalingam, G., Brown, K., Ramsay, M. E., Ladhani, S., \& Moss, P. (2021). Robust SARS-

CoV-2-specific T cell immunity is maintained at 6 months following primary infection.

Nature Immunology, 22(5), 620-626. doi: 10.1038/s41590-021-00902-8

\section{Legends}

Figure 1. SARS-CoV-2 S protein including the ectodomain (residues 19-1207) without native signal peptide. The furin cleavage site was removed (GSAS mutations) and residues at positions $986(\mathrm{~K})$ and $987(\mathrm{~V})$ were mutated to proline. The C-terminal included a 4 fibritin trimerization domain, a TEV protease cleavage site, and a histidine tag.

Figure 2. Rachiplusia nu larvae. a. A batch of 500 fifth-instar larvae. b. Injection of the recombinant baculovirus near the third prolegs.

Figure 3. Purification of $S$ protein by IMAC. a. SDS-PAGE with Coomassie blue staining. b. Western blot with DAB staining. Lanes: MK. molecular weight marker. 1. Larval extract (input). 2. Passthrough. 3. Wash fraction with $80 \mathrm{mM}$ imidazole. 4. Elution fraction with $500 \mathrm{mM}$ imidazole.

Figure 4. Size exclusion analysis of S protein purified by IMAC. a) Chromatogram showing the elution profile of S protein in IMAC. The void volume (Blue dextran) of the column is $\sim 8.8 \mathrm{ml}$, and the monomeric $(\sim 67 \mathrm{kDa})$ and dimeric $(\sim 140 \mathrm{kDa})$ forms of Bovine Serum Albumin (BSA) eluting at $\sim 12.5 \mathrm{ml}$ and $14.4 \mathrm{ml}$, respectively, are shown for reference with bars at the top of the chromatogram. The asterisk indicates the peak containing Spike trimer. Fractions subjected to WB staining with ECL (from 2 to 14) are indicated at the bottom of the chromatogram. 4b) WB of SEC eluted fractions. Protein was revealed using an anti 6xHis tag antibody and ECL. Lane M, molecular weight 
markers; lane C, positive control; lane 1, input; lanes 2 to 14 correspond to respective fractions obtained from the SEC column.

Figure 5: Analysis of ELISA performance resulting from the study of 83 sera from normal control individuals and 98 sera from COVID-19 patients. (A) Sensitivity curve (o) and specificity (x) as a function of the possible cut-off values. The vertical dashed line indicates the cut-off value with the optimized sensitivity and specificity parameters (cutoff = 3.0). (B) ROC curve analysis of ELISA, AUC is included.

Figure 6: Antibodies anti-SARS-CoV-2 results obtained by ELISA in sera from normal control individuals and sera from COVID 19 patients IgG positive and negative by COVIDAR IgG ELISA test. Results are expressed as SDs. The cut-off value (SDs > 3.0) is indicated by a dotted line and medians for each population are indicated as a full line $\left({ }^{* * *} \mathrm{p}<0.0001\right)$. The values for the dots found on the cut-off line are as follow: Controls subjects ( $n=3): 2.81,3.21$ and 2.86; Patients COVIDAR IgG $+(n=1): 2.81$ and Patients COVIDAR IgG - $(\mathrm{n}=1): 3.17$.

Figures

Figure 1

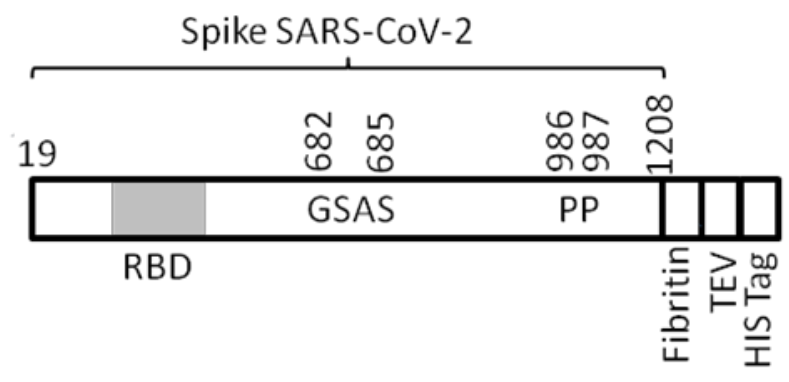

This article is protected by copyright. All rights reserved. 
Figure 2

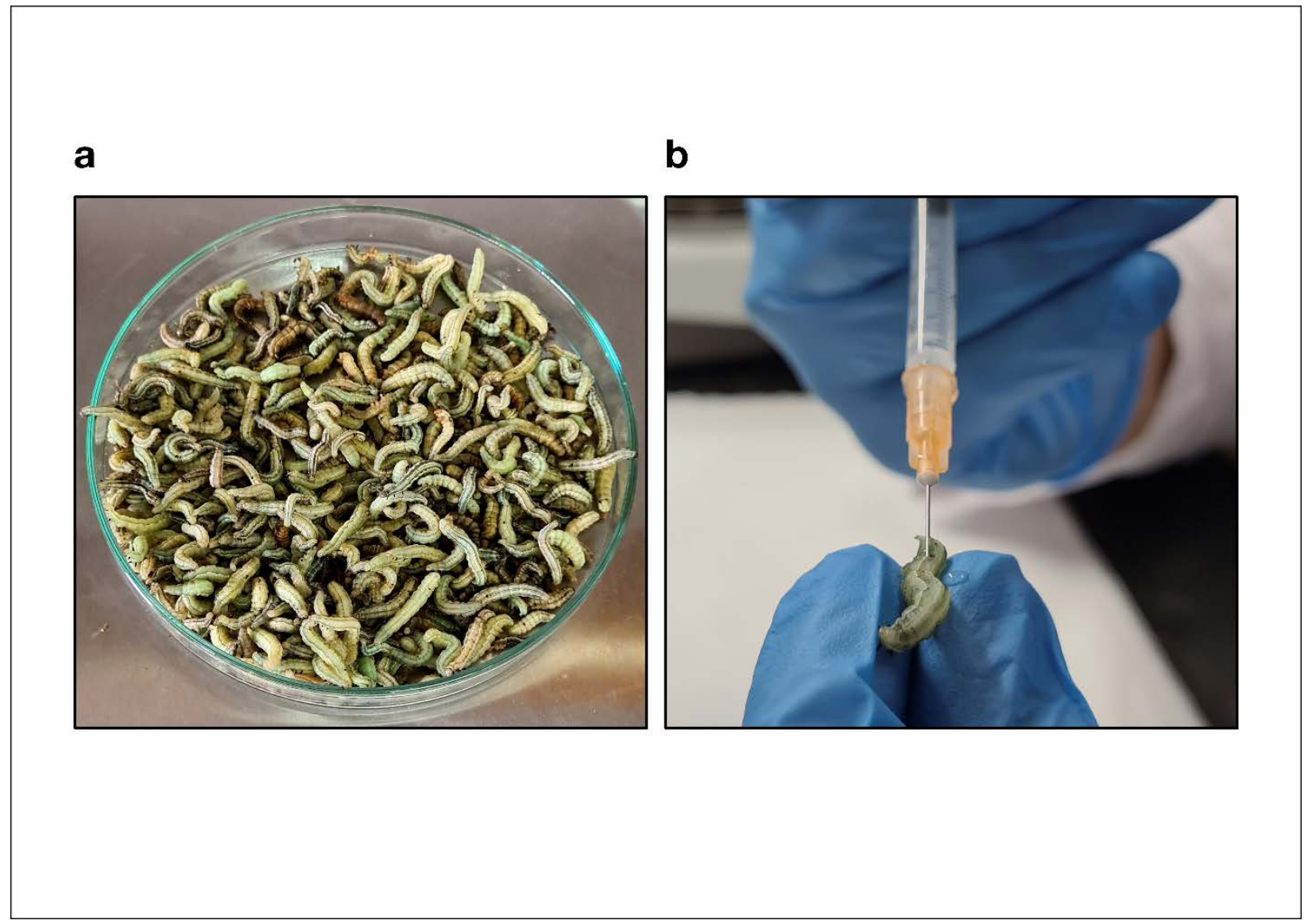

This article is protected by copyright. All rights reserved. 
Figure 3
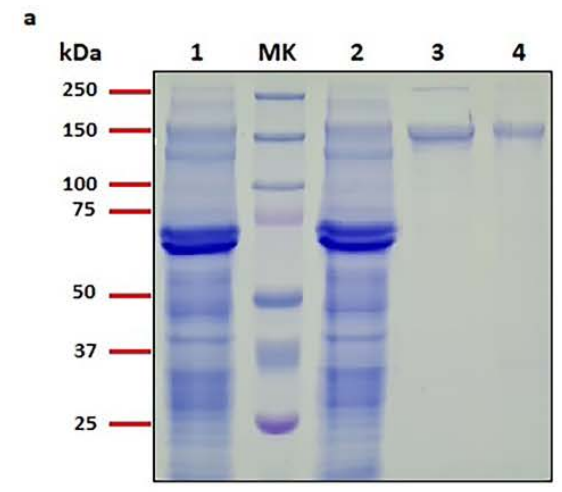

b

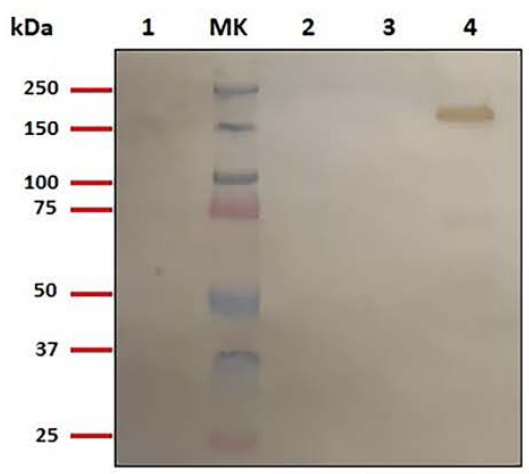

This article is protected by copyright. All rights reserved. 
Figure 4
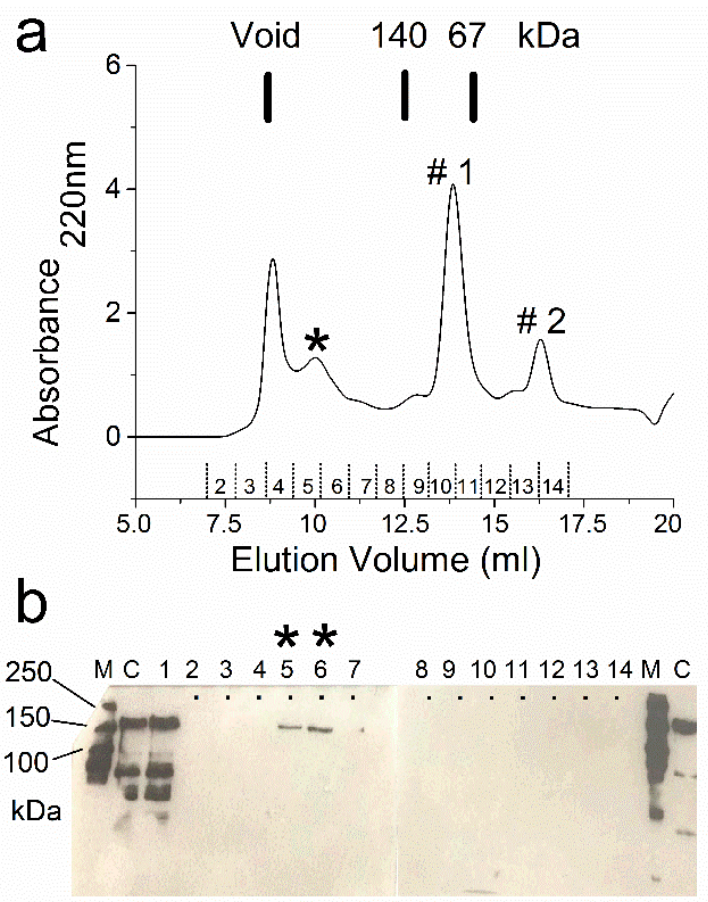

Figure 5

$\mathbf{A}$

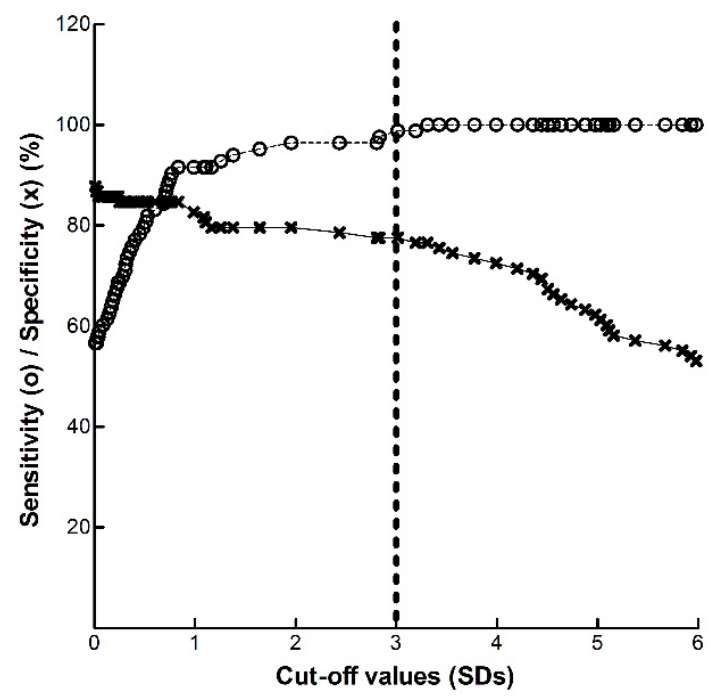

B

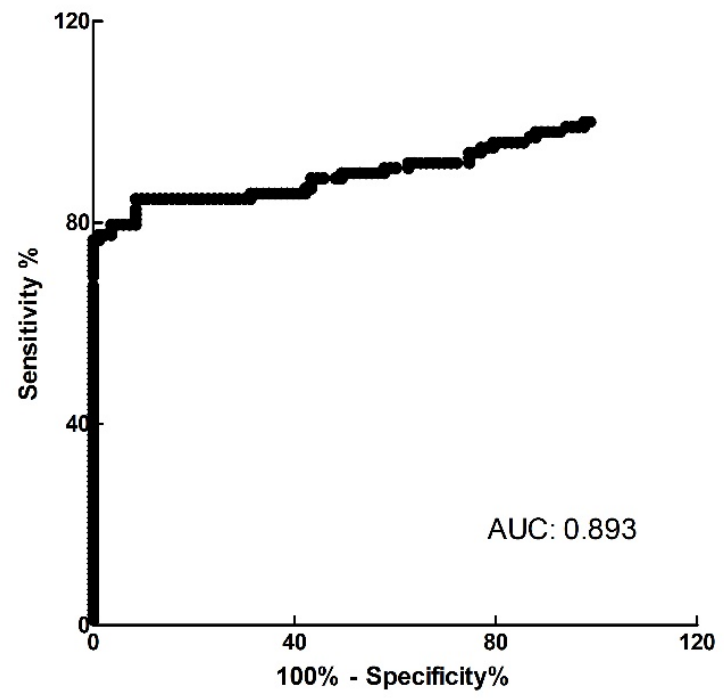

This article is protected by copyright. All rights reserved. 
Figure 6
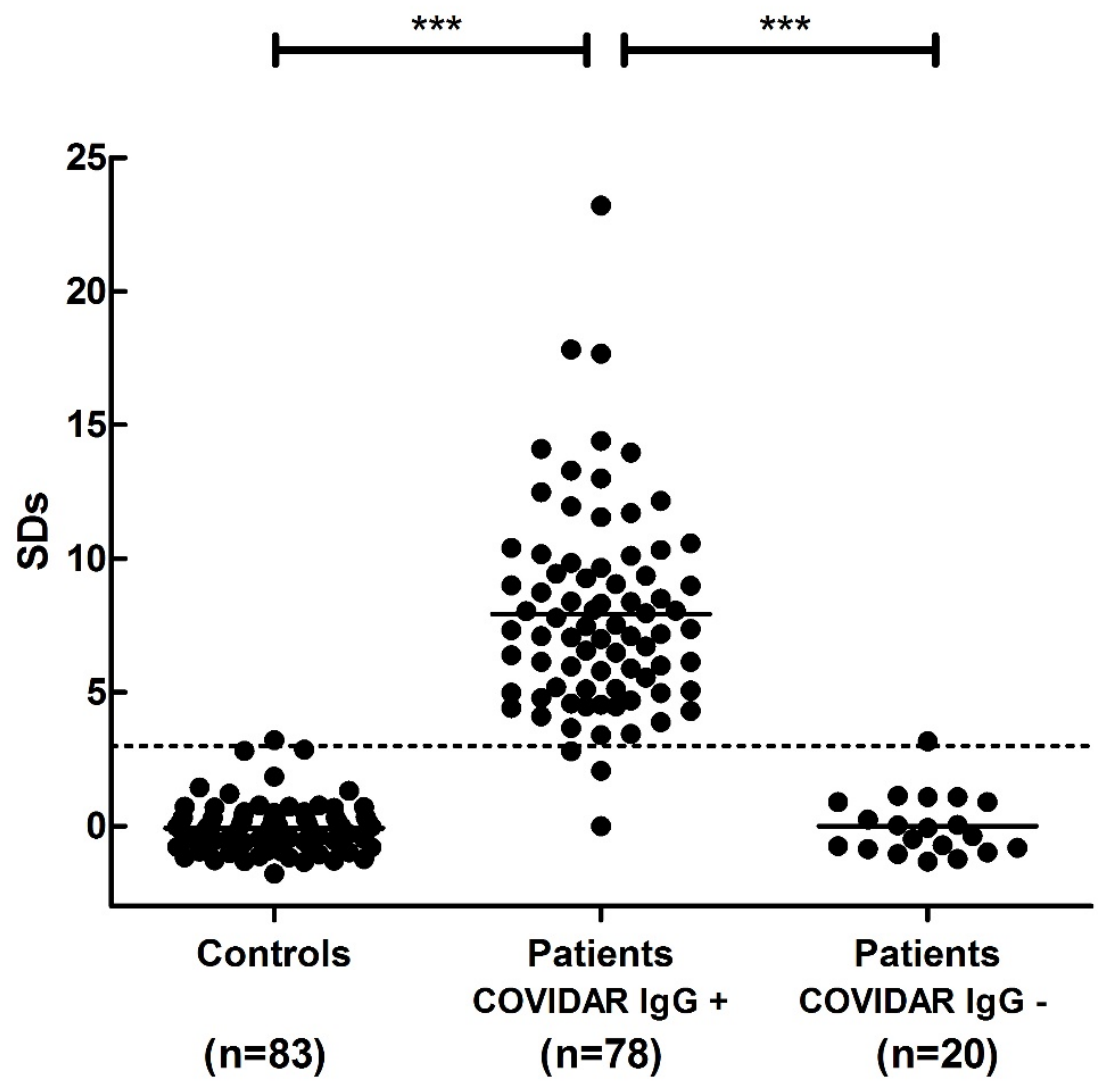

This article is protected by copyright. All rights reserved. 